\title{
The Effectiveness of a Music and Movement Program for Traditional Dance Teaching on Primary School Students' Intrinsic Motivation and Self - Reported Patterns of Lesson Participation
}

Lykesas Georgios 1

Dania Aspasia²

Koutsouba Maria ${ }^{2}$

Nikolaki Evgenia²

Tyrovola Basiliki

\author{
${ }^{1}$ Department of Physical Education and Sport Science, Aristotle University of Thessaloniki, Greece \\ 2Department of Physical Education and Sport Science, National and Kapodistrian University of Athens, Greece
}

Doi:10.5901/mjss.2017.v8n1p227

\section{Abstract}

Research evidence on traditional dance teaching has shown how important it is for primary school education to institute reforms and present new ways of intervention in order to contribute effectively to the overall development of the child's personality. The aim of this research is a) to demonstrate the effectiveness of a music and movement instructional program on traditional dance learning, in terms of primary school students patterns of self-reported positive learning experiences and active lesson participation and b) to examine its impact on students' internal motivation to play and dance with a more enjoyable and creative mood. During a period of six months 80 students (34 boys and 46 girls) aged between 9-10 years old, took part in the research. They were divided into two groups, the experimental group $(N=40)$ and control group $(N=40)$. The experimental group was taught Greek traditional dances according to a Music and Movement teaching model, while the control group was taught the same dances with a direct teaching model. The impact of the two models on students' motivation to participate actively during the lesson was tested with the use of the Intrinsic Motivation Inventory (IMI). The results showed that the use of Music and Movement teaching models can have a positive impact on students' intrinsic motivation and active participation in the course of traditional dance.

Keywords: teaching methods, traditional dance, Music and Movement program, primary school education

\section{Introduction}

Traditional dance is a multidimensional experience that contributes decisively to the child's holistic development, educating in a way that combines feelings and emotions with logic and motor skills (Sanderson, 1988). School education must preserve and pass on to new generations all the elements of folk culture which are "alive" even today and rich in traditional elements, being thus a source of knowledge of a culture's folk tradition (Girke, 1982; Lykesas \& Zachopoulou, 2006; Mason, 2014). In relation to the above, the need for a more integrated approach to Physical Education teaching and particularly Greek traditional dance teaching, one that would help students have more positive psychomotor learning experiences, has led researchers to the development of new teaching models based on music and movement, such as the Music and Movement educational model (Lykesas, 2002; Lykesas et al, 2009).

Music educational systems were born as a result of some pedagogues' need to create a more scientific and comprehensive approach to the process of music teaching, one that would combine music and movement in order to facilitate young children's understanding of musical concepts. Through this approach, music education could derive new, more positive outcomes which could help its advancement. The new music educational methods brought a sweeping revolution in education worldwide and the importance of Music and Movement education was undoubtedly recognized for its contribution to the child's holistic and multifaceted development (Haselbach, 1978; Nye \& Nye, 1985; Mason, 2011).

The ultimate value of these systems layed in the fact that they added new beliefs to the educational process, creating thus something as unusual and innovative as the concept of goal and outcome. For the first time, the lesson was 
more alive and had flow and a creative mood for discovery. The lesson design now had a specific target plan for what children would learn and nothing was left to chance. Through experimentation, music systems virtually changed the direction of education both in the fields of music and movement teaching (Siemens, 1969; Matey, 1978, 1992; Moore, 1984; Androutsos, 1995; Lykesas, 2002).

Within music teaching, research has showed that learning is achieved more effectively when the student participates in the process with his natural self, combining music and movement. Movement, is a part of all humans' spontaneous action and this fact enables the pedagogue to use movement to achieve his/her teaching goals (Lykesas, et al., 2008) and help his/her students experience and understand music immediately and deeply (Lykesas \& Zachopoulou, 2006).

In dance education, the combined use of movement, music and speech created teaching models that were called Music and Movement models of teaching (MMO). These models create a unified whole, without one being subordinate to the other. The MMO model of dance education is a productive teaching model based on students' active participation and experiential learning. It uses experimentation, exploration, observation, freedom of expression and creative improvisation, all aimed at developing children's imagination, and encouraging them to explore and facilitate their learning in an atmosphere of acceptance, with a variety of activities, alternatives and views (Feudel, 1956; Sergi, 1987; Karageorghis, et al., 1997).

The positive effects of music on exercise, sport and athlete performance have been proved up to now by a variety of research (Hume et al, 1992; Becker et al, 1994; Ferguson et al, 1994; Ward et al, 1995). Furthermore, psychological states of feeling good, having less stress and depression, being more confident and alive, have empirically been associated with participation in physical activity accompanied by music (Morgan et al, 1970; Bubner et al., 1982). Gfeller (1988) argues that music can create thoughts and inspire physical activity, leading to improvisation. Douglas (1985) argues that the melody and harmony of music affect the listener's mood and modulate his/her way of interpreting and understanding music. The pedagogical basis of the MMO teaching models was influenced by the theory of Johann Heinrich Pestalozzi (1764-1827), which rejected practices of content memorization and replaced them with practices of observation, experimentation and reasoning (Antonakakis, 1996). According to this theory, great significance was given to the child's a) mood for action, b) group belonging and participation, c) development of creativity, d) self - motivation and imagination, and e) aesthetic education. Through creative movement and music activities, the child comes to know the dance art, and simultaneously cultivates and develops abilities and skills needed to perform traditional dances. The most important music pedagogues who stood at the forefront of the establishment and development of systems for music and movement education were Emile Jaques Dalcroze, Zoltan Kodaly, Carl Orff and Rudolf Laban.

Emile Jaques Dalcroze (1865-1950), a music pedagogue from Switzerland, was the first to introduce a system of MMO education (Matey, 1978). His system is known as Dalcroze Eurhythmics (1921). Dalcroze believed that the problem of children's of lack of rhythm could be solved by activating their body both in its total and partial movement. With the belief that the human body is a musical instrument which could interpret the data and laws of music, the Dalcroze system taught "eurhythmy" to young children (Matey, 1978; Kugler, 1991). The basic principle of this system is muscular experience, which is based on physical movement. Performed and expressed through spatial relations, time and energy, physical movement may teach a real musical and rhythmic sensitivity, that Dalcroze calls "Muscular rhythmical Feeling "(Zachariadi, 1998). These basic principles of the Dalcroze method support the integration of creative movement activities in the school environment and in particular in the teaching of traditional dance. (Androutsos, 1995).

The music - education methodology of Zoltan Kodaly (1882-1958) asserted that music, like language, is a code of communication. The understanding of music requires an ability to read and write a music track. During music reading, elements that are present in the musical text, such as rhythm, melody, scales, phrases, structure, harmony and dynamics should be identified. Furthermore, musicality and knowledge are acquired through the use of voice, which is the first physical instrument of the child (Kodaly, 1974). The teaching techniques to which the Kodaly method applies for the development of musical perception are "the relative solfa system, hand - mimics or sensory - motor activity and rhythmic syllables". He believed, Hungarian folk songs, and particularly choral songs, traditional music and traditional rhythms have a significant place as a material for the musical education of young children, (Emperiadou, 1995; Damianou-Marini, 1998).

Based on Dalcroze's ideas, the music teacher and composer Carl Orff (1895-1982) gave a new impetus to the development of music educational methods, adding speech to music and movement, with the "Orff - Schulwerk», system of MMO school training, entitled "Elemental Music and Movement Education". In his teaching and composing work, Orff approached music with its 'Platonic' dimension and importance, which focuses on speech (expression of thought). According to Orff (1963), the child needs to directly experience the stimuli through movement, play and enjoyably active experience (Donaldson, 1978). Orff established the close relationship between music, speech and dance, giving a new 
dimension to the power of rhythm. He also encouraged children to improvise, to learn themselves through spontaneous music and dance creation and thereby experience music through their own discovery. The new elements introduced by Carl Orff in MMO education were improvisation (individual, team, free, guided, musical, motor, verbal), rhythm (music, movement, speech), creative - expressive, movement - dance, voice - speech - singing, musical instruments (rhythmic playing with percussion instruments, Orff instruments, improvised instruments and items arising during the creative process), and drama (mimicking, dramatic play) (Matey, 1978; Androutsos , 1995; Antonakakis, 1996; Alexiadou, 1999).

Rudolf Laban (1879-1958), a pedagogue of movement and rhythm, was a student of Dalcroze who was influenced by the principles of Eurhythmics and was the first to introduce the conceptual framework of creative movement (Matey, 1978; Laban, 1981; Koutsouba , 2005; Tyrovola \& Koutsouba, 2006). By observing individual movement behavior, Laban found that movement provides a wealth of information about human behavior in various circumstances. Laban's Movement theory (Effort System), is based on spontaneous effort, which is an inner human impulse that is a basic prerequisite for the performance of any kind of movement (Laban, 1998; Koliopoulou, 2000; Koutsouba, 2000, 2005; Dania, 2009, 2013). Laban expressed the view that a child's inner impulse to perform instinctively dance moves brings the child to the area of the flow and expressiveness of movement (Tsapakidou, et al., 2001; Tyrovola \& Koutsouba, 2006; Lykesas, et al., 2014).

Embedded in the school curriculum, spontaneous and creative movement, can be an effective tool for the education in general and dance or traditional dance education in particular (Theodorakou, 1996; Karageorghis, et al., 1997; Chen et al., 2001). Creative movement contributes to the development of children's motor abilities and expressive skills by expanding their creativity and adventurous disposition (Hernandez-Peon, 1961; Capel, 1986; Kraft, 1986; Purcell, 1994). Therefore, the development and implementation of new educational programs designed on the basis of creative movement is deemed appropriate, especially in the case of traditional dance teaching.

According to Karfis and Ziaka (2009), traditional dance must be treated as a whole during its teaching, taking into account many interrelated dimensions and parameters such as technique, style, creativity, communication, functionality and symbolism. In Greece, traditional dance is taught as a compulsory subject in the Physical Education (PE) curriculum of primary and secondary education (Greek Ministry of Education and Religious Affairs and Pedagogical Institute, 2006). In the context of primary PE, former research projects that tested the implementation of new models on Greek traditional dance teaching brought to light some thoughts concerning not only the content and methods of dance teaching but also students' patterns of participation in the school subject of traditional dance (Lykesas, 2002; Lykesas et al, 2006; Lykesas, et al., 2010).

Building on these thoughts and remarks, the aim of the present research project is a) to demonstrate the effectiveness of a music and movement intervention program on traditional dance learning, in terms of primary school students' reported patterns of positive learning experiences and active lesson participation and b) to examine its impact on their internal motivation to play and dance with a more enjoyable and creative mood.

\section{Method}

\subsection{Subjects}

80 students (34 boys and 46 girls), aged 9-10 years old were given parental consent to participate in the research program. The program was conducted in two primary schools $\left(105^{\text {th }}\right.$ and $109^{\text {th }}$ primary schools in the region Ano Toumba, Thessaloniki) from November 2015 to May 2016. At the beginning of the research, students were randomly divided into two groups an experimental group (two classes from the $109^{\text {th }}$ school, $\mathrm{N}_{1}=40$ students) and a control group (two classes from the $105^{\text {th }}$ school, $\mathrm{N}_{2}=40$ students) (Table 1). During the period of the intervention all students were present in all lessons.

Table 1. Distribution of students across the two groups at the beginning of the intervention

\begin{tabular}{lcc}
\hline Group & $(\mathrm{N})$ & $\%$ \\
\hline Experimental group & 40 & 50 \\
\hline Control group & 40 & 50 \\
\hline Total & 80 & 100 \\
\hline
\end{tabular}

Over the eight-month period, a Music and Movement (MMO) teaching model was implemented in the experimental 
group's Physical Education (PE) units, which gradually proceeded to the teaching of Greek traditional dance. In the same period, the control group followed the curriculum guidelines for primary school Greek traditional dance teaching, as proposed by the Greek Ministry of Education and Religious Affairs and Pedagogical Institute (2006). At the beginning of the research, both schools' directors were informed about the aim of the new program and their written consent was given. The research process was carried out in the presence of all research authors.

\subsection{Intervention Program}

The teaching method applied in the experimental group's units was a student-centered method based on the principles of MMO education. Particularly, the teaching method was a combination of the guided - discovery method and the divergent production method, as proposed by the Mosston and Ashworth Spectrum of teaching Styles (Mosston \& Ashworth 1994). The intervention program included music and movement activities aimed at developing basic movement skills and concepts (i.e. body control, rhythmic ability, space awareness etc.) and were presented within scenarios of dance drama movements and games. Contemporary and popular music was used in the experimental group units, followed by Greek traditional music.

The development and implementation of the proposed MMO teaching model, was divided into the following eight phases, regarding the expected student learning outcomes and their accompanying teaching practices and activities:

1. Body activation, awareness and control

Body activation, awareness and control activities were set at the foundation phase of movement and skill learning and practice. During these activities, students learned how to be aware of their various body parts while moving, as well as different ways with which they could move while controlling the type and speed of their movements.

2. Realization and practice of fundamental movement concepts (flow, weight, space, time)

According to the principles of Laban Movement theory, the following activities were used in this phase in order to familiarize primary school students with the movement concepts of flow, weight, space and time:

- Activities for the development of dance performance and expressiveness (skillful use of movement for emotion sharing and transmission).

- Activities for the exploration of movement elements in regard to traditional dance rhythms.

- Activities for the exploration of the use of space (low, medium and high movement), in regard to continuous or bound flow of movement and strong or light weight movement. Regarding the timing of movement, they learned to move with both slow and fast tempo, to stop (pause), accelerate and decelerate, concurrently and sequentially.

3. Familiarization with the concept of rhythm

Introductory name - game activities and get - acquainted games were used in this phase for the development of students' rhythmic response, such as the rhythmic speech games, singing games, hand, leg and whole body stamping or clapping games, vocal sound and rhythmic movement games. Students practiced with the basic characteristics of music, rhythmic accuracy, rhythmic meter and intensity, rhythmic pauses and musical phrases, by using simple rhythms like 2/4, 4/4, 3/4, 6 / 8 etc. and exploring non-symmetrical rhythms, such $7 / 8,9 / 8$, etc.

4. Motor coordination practice

The activities in this phase were designed so as to facilitate students' body part coordination with the music rhythm. Simple parallel movement activities were initially used followed by simple alternating, double parallel and double alternating movement activities.

5. Rhythmic ability game - like practice

The activities used in this phase were designed to help young students feel the rhythm and develop their ability to synchronize their movements to music. Within developmentally designed game activities, students had the opportunity to improvise, and suggest various ways of rhythmic movement and performance. These spontaneously improvised simple and complex dance motor patterns and shapes in space were related to the specific dance patterns that were traced in the structure and form of Greek traditional dances.

6. Familiarization with music instruments, dance sounds and rhythms

During this phase, the content of rhythmic practice activities included the construction of self-improvised musical instruments by the students themselves. With these instruments a small orchestra was created within each intervention class. In their orchestra, students learned to improvise, present and exchange musical 
ideas, while learning to coordinate and cooperate with their peers and gradually come to know the basic principles of homophonic and polyphonic music.

7. Development of the ability to dramatize a certain theme

At this phase of the research, students chose or suggested a specific theme from history and mythology, according which they guided their expressive and creative abilities in directing stage projects, for theater playing, music performing and dancing.

8. Traditional dance learning

After having participated in the above activities, through which they were taught basic movement and music skills and concepts, students were ready to start participating in the traditional dance learning process. With the PE teacher's guidance, students were asked to create separate movement patterns and a movement choreography, all of which corresponded to traditional dance movement motifs. Then the PE teacher divided the choreography into different parts which the students had to analyze and then perform dance to the rhythm of a song of their preference.

During this process, students were effortlessly introduced to Greek traditional dance learning, through experiential learning activities of music and movement improvisation and drama, which were a basic part of their daily dance curriculum. In this way, movement, music and song practice, even in the form of circle activities, was presented to students in a game - like way as a form of playful experience and connection to their country's known and unknown culture.

In contrast to the above, the teaching method that was applied in the control group's units was a direct teaching method that used only the teacher's demonstrations and guidance in the rhythm of traditional dance music, as suggested by the primary PE curriculum (Greek Ministry of Education and Religious Affairs and Pedagogical Institute, 2006). This is what is implemented for the teaching of traditional dance in most Greek schools nowadays. Relevant research evidence has shown that students - and particularly boys - usually show a negative attitude and unwillingness to participate in traditional dance lessons carried out with this method (Van Wersch et al, 1992; Biddle et al, 1995).

\subsection{Experimental procedure}

At the beginning of the research, and before the start of the program (first unit), pretest measurements were conducted. For each group, experimental and control, a total of twenty- two traditional dance teaching units were completed, with units taking place twice a week and lasting 45 minutes each. In both groups, the teaching content included the following dances, which were taught in the same order: Syrtos "Sta Tria", fast Hasapikos, Zonaradikos, Ai Giorgis, Tsourapia, Syrtos of the islands, Tsakonikos, Enteka, Tik and Tsamikos. Some of the selected dances were included in the primary PE curriculum (Greek Ministry of Education and Religious Affairs and Pedagogical Institute, 2006), while some others were local dances with a simple dance form. In both schools, all MMO were taught by the school's PE teacher (lesson coordinator), while throughout the research process the research authors, together with the general teacher of each class, were present as observers (Dania, et al., 2009).

After the end of intervention program, and during the last week of the research, post measurements were carried out under the same conditions. In both groups (experimental and control), the post-test measurement concerned the assessment of students' attitudes regarding their extent of acceptance and manner of participation in traditional dance courses.

\subsection{Measurements}

Research data was collected with the use of the Intrinsic Motivation Inventory (IMI) (Ryan, 1982; McAuley, Duncan \& Tammen, 1989), which is specially designed for primary school children. The IMI inventory has been adapted by Barkoukis, Zahariadis, Govlitsioti and Tsorbatzoudis (1998) to be used with those involved in dance learning and includes 16 closed - type questions, which evaluate both genders' (boys and girls) attitudes and degree of acceptance and participation in the subject of traditional dance. In the present case, participants' total scores in the sixteen IMI questions were assessed as the research dependent variables. Before the application of the intervention program the overall Cronbach alpha reliability was .93 while at the end of the program it was set at .96 .

\subsection{Statistical analyses}

For the analysis of the data the statistical programme SPSS 18.0 for Windows was used. Particularly, descriptive 
statistics regarding students' participation profiles during the research, along with frequency distribution graphs were employed. Between group comparisons of participants' total IMI scores were carried out with the use of independent samples t-tests with the significance level set at 0.05 .

\section{Results}

Students' participation profiles ( $N$, percentages \%), per group and gender, across the two phases of the study are depicted in Table 2. From Table 2 it is evident that all students in the experimental group were present in both measurements, while similar participation profiles were not evident for students in the control group. Even though at the beginning of the research 40 students were allocated to the control group, after the end of the program and during the post measurement, only 19 of them were willing to participate actively ( 6 boys and 13 girls). The rest of the students seemed to adopt an avoidance stance towards the traditional dance lessons, which, in the control group, were carried out with a teacher-centered, reproductive style. Thus, regarding the control group, only these 19 students' responses were included in the post-test analyses.

Table 2. Students participation profiles during the pre and post measurements

\begin{tabular}{cccccc}
\hline & & \multicolumn{2}{c}{ Pre -test } & \multicolumn{2}{c}{ Post - test } \\
& & Boys & Girls & Boys & Girls \\
\hline Experimental & $\mathrm{N}$ & 20 & 20 & 20 & 20 \\
& $\%$ & $50 \%$ & $50 \%$ & $50 \%$ & $50 \%$ \\
\hline Control & $\mathrm{N}$ & 14 & 26 & 6 & 13 \\
& $\%$ & $35 \%$ & $65 \%$ & $31,6 \%$ & $68,4 \%$ \\
\hline Total & $\mathrm{N}$ & 38 & 42 & 26 & 33 \\
& $\%$ & $47.5 \%$ & $52.5 \%$ & $41,4 \%$ & $55,9 \%$ \\
\hline
\end{tabular}

On the contrary, the experimental group's participation profiles proved to be completely different. All students, boys and girls $(\mathrm{N}=40)$ in the 109th primary school participated actively in the MMO lessons and were present in both measurements. (Figure 1).

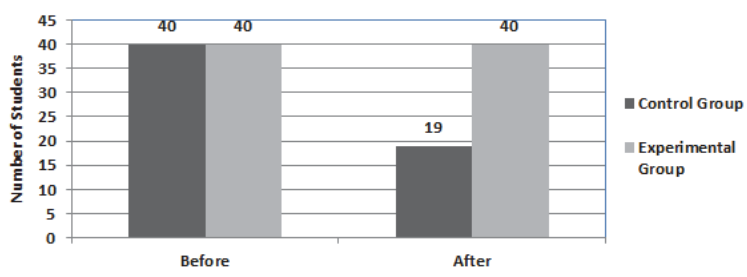

Figure 1. Students' participation profiles per group, gender and measurement

As far as the between group comparisons are concerned, the results of the independent samples t-tests are depicted in Table 3.

Table 3. t-Test results comparing experimental and control group scores at pre and post measurements

\begin{tabular}{|c|c|c|c|c|c|c|c|c|c|c|}
\hline \multirow[t]{2}{*}{ Group } & \multicolumn{2}{|c|}{ Mean (M) } & \multicolumn{2}{|c|}{ Standard Deviation (SD) } & \multicolumn{2}{|c|}{ df } & \multicolumn{2}{|c|}{$\mathrm{t}$} & \multicolumn{2}{|c|}{ ES } \\
\hline & Pre & Post & Pre & Post & Pre & Post & Pre & Post & Pre & Post \\
\hline Experimental & 2.56 & 4.33 & .83 & .28 & & & & & & \\
\hline Control & 2.24 & 1.47 & .64 & .70 & 57 & 21 & 1.98 & $13.84^{\star *}$ & .553 & 3.86 \\
\hline Total & 2.40 & 3.76 & 1.47 & .95 & & & & & & \\
\hline
\end{tabular}

${ }^{*} \mathrm{p}<.01$, Effect size based on Cohen's d measure

From the results, it was found that even though at the beginning of the research, the mean IMI scores did not differ between the experimental $(M=2.56, S D=.83, N=40)$ and the control group $(M=2.24, S D=.64, N=40), t(80)=1.98$, 
$p<.05$, at the end of the intervention program, a statistical significance was found between the two groups with $t(59)=$ 13.84, $p<.01(\mathrm{M}=4.33, \mathrm{SD}=.28, \mathrm{~N}=40$ and $\mathrm{M}=1.47, \mathrm{SD}=.60, \mathrm{~N}=19$, for experimental and control group respectively).

Concerning each gender's mean scores during the study, it was found that for girls in the experimental group the IMI total scores were higher at the end of the program $(M=4.33, S D=.286)$, in comparison with their peer girl scores in the control group $(M=3.50, S D=.403)$. Similar were the findings for boys in the experimental group $(M=4.33, S D=$ $.286)$, in comparison with their peers in the control group $(M=3.73, S D=.411)$. These differences were evident, independently of the fact that all students' total IMI scores did not differ significantly prior the beginning of the research.

\section{Discussion}

The analysis of the research results showed that by the end of the program the experimental group showed a generally more positive attitude and behavior towards traditional dance learning, compared to that of their peers in the control group. Irrespective of students' gender, it was found that the MMO teaching model helped students in the experimental group to learn and understand traditional dance at a faster pace and with a more enjoyable, creative and productive manner. This positive finding was seen in the absence of differences between boys' and girls' participation profiles at the end of the intervention program.

The use of the MMO teaching model in this group provided a powerful tool for the development of students' creative skills which increased qualitatively during the course of the units. Within the MMO units, each new locomotor activity or exercise was a part of students' creative and self-directed learning. This fact made the newly acquired knowledge and skills more interesting and enjoyable.

Similar findings were noted in a project carried out by Douglas (1985), which stressed the importance of creating of a pleasant learning environment for the development of students' skills and performance. Music was a determinant teaching medium to this end, something which is in agreement with the findings of a study (Karageorghis, et al., 1997). The latter proved that music is a motivator that helps to create a climate of freedom. In this climate students are given the opportunity to use their curiosity during the learning process, to explore, develop and create, either individually or with their peers. Donaldson (1978) agrees with the findings of Douglas, stating that through MMO programs of music and dance education, students become more skilful by performing movements that require spontaneity and expressiveness.

The present case MMO model was a creative teaching model in the sense that it gave great importance to each student's individuality and learning style. In this way, it promoted individual self - motivation and students' initiative to explore, discover and experiment at their own pace and with spontaneous and expressive movement reactions to the rhythm of music (Purcell, 1994). Morgan et al. (1970) and Bubner et al. (1982), confirm that spontaneous activities or reactions to teacher directed stimuli can promote children's motor creativity. When they are embedded within the school curriculum, such activities provide a motivational tool that makes the lesson more pleasant and interesting. Chen et al (2001) further note that students' participation and interest are further guaranteed when the applied activities or programs delineate distribution of students' roles that lead to specific learning goals.

In contrast to the MMO model, the level of intrinsic motivation that was recorded for students in the control group remained at the same low level during the implementation of the teacher - directed instructional method. Students in this group seemed to adopt a negative attitude towards traditional dance, being rather indifferent and nervous during the learning process. This attitude was more intense for the boys in this group, all of whom seemed to remain approximately at the same level of intrinsic motivation, that recorded before the beginning of the research.

The results also showed that throughout the program, students in the control group tried to find reasons and excuses for not participating in the lessons. Their indifference and frequently recorded aggressive behavior caused several problems that made both the teaching of movement and skills and the inter - student relationships rather difficult. It was not surprising though that students in this group recorded an almost $50 \%$ negative attitude towards the lesson during the post measurement (Tables 2). These difficulties hindered the smooth flow of the lessons and caused further declines in students' interest for traditional dance. In such a negative learning environment, it was difficult for the teacher to give students further information regarding each dance's cultural or folk elements, which were finally omitted from the content of the units.

\section{Conclusions - Suggestions}

The present research shows how necessary it is for the educational system, especially in the primary school years, to adopt reforms and present new ways of instruction, in order to contribute effectively to the holistic development of 
students' personalities (Mason, 2011). More than ever, there is an urgent need nowadays for educational practices that build on students' already acquired knowledge and motor experiences in order to enhance their creativity and help them progress within a context of joy, satisfaction and fun. Such a context is especially important for traditional dance teaching, since it gives students the chance to participate in more effective terms that will foster their social skills and promote their willingness to learn and participate actively. The use of MMO teaching models together with the implementation of student-centered methods could support traditional dance pedagogy and its impact on students' psychomotor, cognitive and social affective development. The ultimate benefit would be the education of healthy, dynamic and independent young citizens, who could cooperate effectively and pass on cultural knowledge as part of the living social fabric.

Since its main purpose is the total harmonic, mental and psychomotor development of children (Sergi, 1987), MMO education is considered essential especially for primary school students' skill development and smooth adaptation to the learning environment (Mason, 2014). As a solid educational theory and practice, MMO education rejects the teaching practices of memorization and passive reception of knowledge and adopts alternative ones such as observation, experimentation and reasoning (Sergi, 1987; Rica, 2004). Seeking a harmonic and balanced body - soul - spirit relationship, it adopts play like practice and group activities that cultivate students' social and aesthetic skills (Matey, 1978; Androutsos, 1995; Laban, 1998). The above skills are extremely important for students' effective interaction within the school context.

Therefore, school education has an obligation to cultivate and activate MMO practices that are developmentally designed to promote every student's learning potential (Lykesas, et al., 2014). At this point it is important to note that education should be seen not only in cognitive terms, but also through the provision of positive experiences (Feudel, 1956). Especially in the first school years, when children are receptive and willing to assimilate new experiences regarding movement, sounds, colors, rhythms and overall aesthetic forms (Greek Ministry of Education and Religious, 2006), school education should foster movement, fantasy and cognition, while building on students' perception and linguistic abilities (Haselbach, 1978; Tsapakidou, et al., 2001; Lykesas \& Zachopoulou, 2006; Lykesas et al, 2009; Lykesas et al, 2014).

Music and Movement education is a pedagogical system for the teaching of music and movement that relies on individual living experience, exploration, observation and creative improvisation. Its underlying philosophy is based on the principles of modern theories from the fields of child psychology, music pedagogy, kinesiology and aesthetic education. Due to this fact, $\mathrm{MMO}$ education can become a relevant approach for multiple educational or scientific fields. However, its adoption by pedagogues of various disciplines remains a challenge that must be met not only by practitioners but also by educational policy makers.

\section{References}

Alexiadou, K. (1999). Music and Movement Carl Orff. Athens. Greece. Journal of Modern Nursery School, 9th, pp. 171-175.

Antroutsos, P. (1995). Music teaching methods. (Ed.) Orpheus. Athens. Greece.

Antonakakis, D. (1996). Carl Orff. (Ed.) Orfefs, Hraklio-Kreta. Greece.

Barkoukls, V., Zahariadis, P., Govlitsioti, V., \& Tsorbatzoudis, H. (1998) Goal orientation and intrinsic motivation in recreational activities. International Conference on Motivation. 6th Workshop on Achievement and Task Motivation. Thessaloniki 27 -30 March 1998. [Abstract book] (Project of the National Dance Association, An Association of the American Alliance for Health, Physical Education, Recreation and Dance, Virginia). pp. 52-53.

Becker, N., Brett, S., Chambliss, C., Crowers, K., Haring, P., Marsh, C. \& Montemayor, R. (1994). Mellow and frenetic antecedent music during athletic performance of children, adults and seniors. Perceptual and Motor Skills, 7(2), pp. 1043-1046.

Biddle, S., Cury, F., Goudas, M., Sarrazin, P., Famose, J.P. \& Durand, M. (1995). Development of scales to measure perceived physical education class climate: a cross national project. British Journal of Educational Psychology, 65 (3), pp. 341-358.

Bubner, C. \& Mienert, C. (1982). Bausteine des Darstellenden Spiels. Hirschgraben Verlag. Frankfurt am Main. Germany.

Capel, S. (1986). Education gymnastics meeting, physical education goals. Journal of Education. Recreation \& Dance, vol. 57 (2), pp. 34-38.

Chen, A., \& Darts, P. (200l) Situational interest in physical education: a function of learning task design. Research Quarterly for Exercise and Sport, 72 (2), pp. 150-164.

Dalcroze, J.E. (1921). Rhythm, Music and Education. The Riverside Press. Trans., Harold F. Rubenstein. London \& Whitstable, 1967.

Damianou - Marini, E. (1998). Basic methodological principles for the implementation of music movement ideas of Zoltan Kodaly. In: Music Education, Proceedings of 1st National Conference of EEME 3, the first volume, pp. 30-38, Thessaloniki. Greece.

Dania, A., Koutsouba, M., Hatzicharistos, D. \& Tyrovola, B. (2009). Research Regarding the Development of Dance Performance Measurement Instruments: A Review. The Journal of Inquiries in Sport \& Physical Education, 7(2), pp. 179-202.

Dania, A. 2009. "Development of a Dance Performance Assessment Instrument. Its Application on Greek Traditional Dance." Published Master's Thesis, University of Athens, Greece. 
Dania, A. 2013. "From Symbols to Movement. The Effect of the Laban-Notation Teaching Method on Greek Traditional Dance Learning." Unpublished PhD diss., National and Kapodestrian University of Athens, Greece.

Donaldson, M. (1978). Children's minds. William Collins Sons \& Co. Glasgow, Scotland.

Douglas, N.W. (1985). The effects of tempo and disposition in music on perceived exertion, brain waves and mood during exercise. Unpublished master's thesis. Pennsylvania State University.

Emperiadou, E. (1995). The music movement method of Zoltan Kodaly. Degree. work, School of Music Studies, Aristotle University of Thessaloniki. Greece.

Feudel, E. (1956). Rhythmisch - musikalische Erziehung. Moeseler Verlag Wolfenbyettel. Germany.

Ferguson, A.R., Carbonneau, M.R. \& Charmbliss, C. (1994). Effects of positive and negative music on performance of a karate drill. Perceptual and Motor Skills, 78 (3), 1217-1218.

Gfeller, K. (1988). Musical components and styles preferred by young adults for aerobic fitness activities. Journal of Music Therapy, 25(1), pp. 28-43.

Girke, D. (1982). Tanzsport in der Schule. Schorndorf. Germany. Verlag Hofmann. Germany.

Greek Ministry of Education and Religious Affairs and Pedagogical Institute (2006). Physical Education in Primary school and Curriculum. Book of teacher. Administration of Physical Education. Textbook Publications, Athens.

Haselbach, B. (1978). Tanzerziehung. verlag Ernst Klett. Stuttgart. Germany.

Hernandez-Peon, R. (1961). The efferent control of afferent signals entering the central nervous system. Annals of New York Academy of Science.

Hume, K.M. \& Crossman, J. (1992). Musical reinforcement swimmers. Journal of Applied Behavior Analysis. 25 (3), pp. 341-347.

Karageorghis, C. I., \& Terry, P. C. (1997) The psychophysical effects of music in sport and exercise: A review. Journal of Sport Behavior, 20 (1), pp. 54-68.

Karfis, B. \& Ziaka, M. (2009). The Greek traditional dance in education. Teaching Proposal. Vivliodiaplous. Thessaloniki. Greece.

Kodaly, Z. (1974). Childen's choirs. In. The Selected writings of Zoltan Kodaly. Budapest. (Ed) Corvina Press.

Kraft, R. E. (1986). Modern programs-current practices in Britain. Journal of Physical Education, Recreation and Dance, 57 (8), pp. 7578.

Koliopoulou, M. (2000). Develop artistic skills in teaching dance. (Ed.) Propompos. In: Culture and Art seven essays on dance, pp. 17-29. Athens. Greece.

Koutsouba, M. (2000). Stylistic analysis in Greek traditional dance, (Ed.) Propompos. In: Culture and Art seven essays on dance, pp. 30-77. Athens. Greece.

Koutsouba, M. (2005). Notation of the dancing movement. From the prehistory to the history of dance. Propompos. Athens. Greece.

Kugler, M. (1991). Zur Entstehung von C.Orffs Schulwerk. In: Rudolf - Dieter Kraemer, Hrsg. Musikpädagogik, Unterricht- ForschungAusbildung. Mainz. Germany.

Laban, R. v. (1981). Der moderne Ausdruckstanz in der Erziehung. Wilhelmshaven.

Laban, R. v. (1998). A Life for Dance. (L. Ullman, Trans.). New York: Theatre Arts Books.

Lykesas, G. (2002). The Teaching process of traditional Greek dances in Primary Education implementing the method of Music and Movement Education. Unpublished PhD dissertation. Aristotle University of Thessaloniki. Greece.

Lykesas, G. \& Zachopoulou, E. (2006). Music and Movement Education as a Form of Motivation in teaching Greek Traditional Dances. Perceptual and Motor Skills, 102 (2), pp. 552- 562.

Lykesas, G \& Koutsouba, M., (2008). The teaching of Greek traditional dance in the school education with the adoption of creative methods of teaching. Journal of Health and Sport Performance, vol. 3, pp. 37-49.

Lykesas, G., Koutsouba, M., \& Tyrovola, V. (2009). Creativity as an approach and teaching method of traditional Greek dance in secondary schools. Studies in Physical Culture \& Tourism, 16(2), pp. 207-14.

Likesas G., Koutsouba, M., \& Tyrovola, B. (2010). Comparison of the teacher and child-centred methods of teaching Greek traditional dance in elementary education in Greece. International Journal of Physical Education, XLVII(3), pp. 25- 33.

Lykesas, G. Tsapakidou, A. \& Tsompanaki, E. (2014). Creative Dance as a Means of Growth and Development of Fundamental Motor Skills for Children in First Grades of Primary Schools in Greece. Asian Journal of Humanities and Social Studies. 2 (1), pp. 211-218.

Mason, H. P. (2011). Music, dance and the total art work: choreomusicology in theory and practice. Research in Dance Education, 13(1), pp. 5 -24.

Mason, H. P. (2014). Tapping the Plate or Hitting the Bottle: Sound and Movement in Self-accompanied and Musician-accompanied Dance, Ethnomusicology Forum, 23(2), pp. 208-228.

Matey, P. (1978). Rhythmic. (Ed.) G.Nakas. Athens. Greece.

Matey, P. (1992). Rhythm. Greek Club of Musical-Kinetic Education Carl Orff. Athens. Greece.

McAuley, e., Duncan, T. \& Tammen, V. (1989). Psychometric properties of the intrinsic motivation inventory in a competitive sport setting: A confirmatory factor analysis. Research Quarterly for Exercise and Sport, 60 (1), pp. 48-58.

Moore, J.L.S. (1984). Rhythm and Movement: An objective analysis of their association with music aptitude. Unpublished doctoral dissertation. University of North Carolina. Greensboro.

Morgan, W.P., Roberts, J.A., Brand, F. \& Feinerman, A.D. (1970). Psychological effects of chronic physical activity. Medicine and Science in Sports and Exercise, 2, pp. 213-217.

Mosston, M., \& Ashworth, S. (1994). Teaching Physical Education. Publishin Company Inc. Macmillan College, U.S.A. 
Nye, R. E., \& Nye, V. T. (1985). Music in the elementary school (5th ed.). Englewood Cliffs, NJ: Prentice-Hall.

Orff,C. (1963). The Schulwerk. Its origin and Aims. Music Educators Journal, 49(5), pp. 69-74.

Pica, R., (2004) "Experiences in movement: Birth to age eight", (3rd ed.), Clifton, Park, NY: Thomson/ Delmar Learning.

Purcell, Th. (1994). Teaching Children Dance. Kendall Park. New Jersey. Human Kinetics.

Ryan, R.M. (1982). Control and information in the intrapersonal sphere: An extension of Cognitive Evaluation Theory. Journal of Personality and Social Psychology, 43, pp. 450-461.

Sanderson, P. (1988). Physical education and dance. In T. Roberts. (Ed.), Encouraging expression: The arts in primary school. Cassell. London.

Sergi, L. (1987). Creative musical education for our children. (Ed.) Gutenberg. Athens. Greece.

Siemens, M. (1969). A comparison of Orff and traditional instructional method in Music. Journal of Research in Music Education 17 (3), pp. 272-285.

Theodorakou, K. (1996). Creativity - Creative movement: Literature review. In: Proceedings of the 1st International Congress of Sport Psychology, pp. 335-340. Komotini. Greece.

Tsapakidou, A. , Zachopoulou, E., \& Zographou, M. (200 1) early young children 's behavior during music and movement program. Journal of Human Movement Studies, 41, pp. 333-345.

Tyrovola V. \& Koutsouba M. (2006). Morphological Method of Teaching Greek Traditional Dance: the Example of the Dances of Pontos. Journal of Music in primary school, vol. 1, pp. 19-32.

Van Wersch, A., Trew, K. \& Turner, I. (1992). Post - primary school pupils' interest in physical education: age and gender differences. British Journal of Educational Psychology, 62 (1), pp. 56-72.

Ward, P. \& Dunaway, S. (1995). Effects of contingent music on laps run in a high school physical education class. The Physical Educator, 52(1), pp. 2-7.

Zachariadi, A. (1998). Music Education, Emile Jaques Dalcroze. Presentation of the Method: Rhythmic. In: Proceedings of the 1st National Conference of EEME 3, the first volume, pp. 23-29. Thessaloniki. Greece. 